\title{
Technique of Functional and Motility Test: How to Perform Antroduodenal Manometry
}

\author{
Tanisa Patcharatrakul ${ }^{1,2}$ and Sutep Gonlachanvit ${ }^{1 *}$ \\ ${ }^{1}$ Gastrointestinal Motility Research Unit, Division of Gastroenterology, Department of Medicine, Chulalongkorn University, Bangkok, Thailand; \\ and ${ }^{2}$ King Chulalongkorn Memorial Hospital, Thai Red Cross Society, Bangkok, Thailand
}

\begin{abstract}
Antroduodenal manometry is one of the methods to evaluate stomach and duodenal motility. This test is a valuable diagnostic tool for gastrointestinal motility disorders especially small intestinal pseudo-obstruction which is difficult to make definite diagnosis by clinical manifestations or radiologic findings. Manometric findings that have no evidence of mechanical obstruction and suggestive of pseudo-obstruction with neuropathy or myopathy can avoid unnecessary surgery and the treatment can be directly targeted. Moreover, among patients who have clinically suspected small intestinal pseudo-obstruction but with normal manometric findings, the alternative diagnosis including psychiatric disorder or other organic disease should be considered. The application of this test to the patients with functional gastrointestinal symptoms especially to find the association of motor abnormalities to the symptom has less impressive yield. Antroduodenal manometry is now readily available only in some tertiary care centers. The aim of this review is to describe the antroduodenal manometry technique, interpretation and clinical utility.

(J Neurogastroenterol Motil 2013;19:395-404)
\end{abstract}

Key Words

Manometry; Gastrointestinal motility; Intestinal pseudo-obstruction

\section{Introduction}

Antroduodenal manometry is a manometric method used for evaluation of stomach and duodenal motility. This test is a valuable diagnostic tool for gastrointestinal (GI) motility disorders especially small intestinal pseudo-obstruction which is difficult to make definite diagnosis by clinical manifestations or radiologic findings. Antroduodenal manometry results have been reported to make a change in diagnosis in $8-15 \%$ of patients with unexplained nausea, vomiting, and abdominal pain at tertiary care center. ${ }^{1}$ Manometric findings that have no evidence of mechanical obstruction and suggestive of pseudo-obstruction with neuropathy or myopathy can avoid unnecessary surgery which resulted in a substantial positive impact on patient management. ${ }^{2}$

\section{Indication for Antroduodenal Manometry -}

Patients who have small bowel dysmotility may present with non-specific symptoms such as abdominal pain, bloating, nausea, vomiting, constipation or diarrhea. Investigations for small bowel dysmotility should be employed in patients who have these symp-

Received: June 24, 2013 Revised: None Accepted: June 25, 2013

(c) This is an Open Access article distributed under the terms of the Creative Commons Attribution Non-Commercial License (http://creativecommons. org/licenses/by-nc/3.0) which permits unrestricted non-commercial use, distribution, and reproduction in any medium, provided the original work is properly cited.

*Correspondence: Sutep Gonlachanvit, MD

Gastrointestinal Motility Research Unit, Division of Gastroenterology, Department of Medicine, Faculty of Medicine,

Chulalongkorn University, Rama 4 Road, Patumwan, Bangkok 10330, Thailand

Financial support: None.

Tel: +66-2-256-4265, Fax: +66-2-252-7839, E-mail: gsutep@hotmail.com

Conflicts of interest: None. 
toms chronically or intermittently and have at least moderate severity of the symptoms which significantly affect their quality of life. Small bowel motility tests should play role in patients with clinically suspected intestinal obstruction but without obstructive cause, symptoms onset since childhood or adolescence, positive family history of intestinal pseudo-obstruction, or having autonomic neuropathy or other underlying diseases which commonly are associated with GI dysmotility such as systemic sclerosis and amyloidosis. ${ }^{3}$

In general, antroduodenal manometry provides benefit among the following groups of patients,

(1) Suspected small intestinal pseudo-obstruction

(2) Unexplained abdominal pain and nausea/vomiting

(3) A part of GI motility tests to exclude diffuse GI motility disorder

Studies demonstrated that patients who had small intestinal pseudo-obstruction had the abnormal motility patterns which were not presented in healthy individuals ${ }^{4}$ and were different from mechanical obstruction. ${ }^{5}$ Moreover, among patients who had clinically suspected small intestinal pseudo-obstruction but with normal manometric findings, the diagnosis was finally turned out to be psychiatric or other organic diseases such as Munchausen syndrome-by-proxy, celiac disease and multiple food intolerance. ${ }^{6,7}$ The manometric abnormalities in intestinal pseudo-obstruction and mechanical obstruction will be described later. Antroduodenal manometry should not be performed in patients with symptoms and signs suggestive of small intestinal obstruction unless mechanical obstruction has been excluded by radiologic or endoscopic methods. In addition, fluid resuscitation, bowel decompression, as well as electrolyte imbalance correction should be done prior to the study if clinically indicated. Antroduodenal manometry should be a part of motility test to exclude diffuse GI dysmotility before colectomy in colonic inertia patients. The small intestinal dysmotility was reported in $60 \%$ of these patients $^{8}$ and the normal antroduodenal manometry result was associated with better long-term post-operative outcome. ${ }^{9}$

\section{Technique and Devices}

Baseline measurements of stomach and small intestinal motility at fasting period as well as the effect of meal on stomach and small intestinal activity at post-prandial period have to be evaluated. Therefore, the patients should fast for at least 8 hours prior to the study and medications that affect GI tract motility have to be withheld for at least 3-7 days.

\section{Devices}

To measure the intraluminal pressure, the instrument requires lumen obliterating contraction to activate pressure transducer on the catheter. Typically, 2 types of catheter have been used for antroduodenal manometry with different advantages and limitations: (1) water perfused and (2) solid state catheter.

\section{Water perfused catheter system}

This catheter has multiple recording side holes with any desirable interval space which usually is $5-10 \mathrm{~cm}$ at duodenal part and $0.5-1 \mathrm{~cm}$ at antral and pyloric part. ${ }^{10}$ Each recording channel is connected with low compliance pneumohydraulic perfusion system with typically perfused rate of $0.1-0.3 \mathrm{~mL} /$ minute. Patients using this system especially who have prolonged recording time may receive large amounts of water from system perfusion and may feel uncomfortable or be stressful due to immobilization. Monitoring of pyloric pressure activities is difficult because of the migration of the recording site in relation to the pyloric sphincter. The catheter with additional transpyloric sleeve (Dent sleeve) that incorporates several closely spaced (3-5 mm) pressure transducers can be positioned across the pylorus and used for sphincter pressure measurement to minimize the effect of catheter movement. ${ }^{11}$ The advantages of water perfused catheter are that it is relatively inexpensive and widely available.

\section{Solid state catheter}

This type of catheter has the microtransducer sensors which are vary in the sensor number and the spacing of each sensor that is placed along distal end of a catheter. The solid state catheter system is highly portable and more comfortable for patients. The system with portable data logger can be used for 24-hour ambulatory antroduodenal manometry monitoring.

Recently, the high-resolution manometry (HRM) system was introduced. This catheter incorporates up to 36 circumferential pressure sensors spaced at 1-2 cm intervals and the data can be displayed as traditional pressure tracings or contour plots which are easily recognized. ${ }^{12,13}$ When comparing the conventional water perfused or solid state system, this high-resolution system is able to demonstrate more details on small bowel pressure profile as well as the pyloric pressure at different contraction phase. ${ }^{12}$ Several pyloric activity abnormalities including atonic pattern or sustained elevation of the pyloric baseline pressure which independently occurred or superimposed on phasic activity, prolonged duration of total pyloric activity during fasting and post-prandial period, as well as a prolonged ( $\geq 3$ minutes) and intense ( $\geq 10 \mathrm{mmHg}$ ) tonic contraction or pylorospasm have 
been described in diabetic gastroparesis patients more than control subjects. ${ }^{14}$ Pyloric injection of botulinum toxin A has been reported to improve patients with gastroparesis in several uncontrolled studies. ${ }^{15-18}$ However, more evidence is needed to determine whether patients with gastroparesis secondary to pyloric spasm diagnosed by the HRM study will receive benefit from the botulinum toxin treatment.

The potential limitation of the HRM technology is that it is very sensitive and frequent movement artifacts as well as physiological artifacts such as respiratory activity and pulsations from nearby major vessels may be confusing. ${ }^{12}$ In addition, the solid state and HRM system are more expensive than water perfused system.

\section{Catheter Placement}

Antroduodenal manometry catheter is usually inserted through the nose under fluoroscopy guidance without using endoscope to avoid duodenal air over-inflation may inhibit antral contraction. ${ }^{19,20}$ However, in some difficult cases such as gastroparesis, catheter placement can be facilitated by using guidewire with endoscopic guidance. Effect of sedatives on intestinal contraction have been reported. Midazolam increased the duration and contraction amplitudes of phase III migratory motor complex (MMC) in the proximal duodenum and shortened the duration of the migrating motor complex. ${ }^{21}$ The catheter should be placed until it lay just beyond the ligament of Treitz or about 20 $\mathrm{cm}$ length in small intestine to adequately evaluate the antral and duodenal activities. ${ }^{10}$ Typically, if using the catheter with 8 site holes, 3 distal recording sites are placed within the duodenum and 5 proximal side holes which have narrower space interval are placed within antrum and pylorus. The catheter location should be checked periodically by fluoroscopy or by normal wave frequency pattern recognition throughout the study and prior to catheter removal at the end of the study. ${ }^{10}$

\section{Study Duration}

Normally, the total recording time for stationary manometry is at least 6 hours; 4 hours for fasting period followed by standard meal ingestion and next 2 hours for studying post-prandial period. ${ }^{22}$ However, the longer ambulatory monitoring is possible when using solid state catheter with mobile recording assemblies. ${ }^{23}$ This system allows 24 hours or more recording time in which more stomach and intestinal contraction patterns during different activities and diurnal motility changes can be revealed. ${ }^{22,24}$ Moreover, the long recording time with multiple meal re- sponses and monitoring at home environment may reduce the intra-individual and inter-individual variability. ${ }^{23,25}$ Studies comparing between ambulatory recording and stationary recording revealed a higher accuracy of ambulatory recording for evaluation of inter-digestive abnormalities and also allows assessment of the relationship between symptoms that may be intermittent with motor abnormalities. ${ }^{26,27}$ The retrograde migration of catheter especially after meal ingestion can lead to incomplete evaluation of abnormal fed response of antrum which may be associated with a number of dysmotility disorders. ${ }^{24,28,29}$ This problem may limit the usefulness of ambulatory recording in which the location of catheter cannot be periodically checked. ${ }^{24,30}$

\section{Provocative Tests}

Provocative test using medications that specifically stimulate stomach and/or small intestine can be performed to demonstrate abnormal responses in these regions. Typically, erythromycin 3 $\mathrm{mg} / \mathrm{kg} / \mathrm{hr}$ infusion and octreotide $100 \mu \mathrm{g}$ subcutaneously have been used for study during fasting state. ${ }^{31-34} \mathrm{~A}$ study in healthy subjects showed that erythromycin induced phasic antral contractions which mimicked MMC within 15 minutes. ${ }^{31}$ These antral phase III contractions had significantly more prolonged duration but similar frequency and propagated into small intestine as the naturally occurring phase. The erythromycin-induced phase III contraction in the proximal duodenum showed no difference in duration and frequency from spontaneously occurring phase. In contrast, the duration of phase III in the proximal jejunum was shorter and had slower migration after erythromycin infusion than naturally occurring phase III. This drug may be used during motility testing to induce antral phase III activity if it fails to occur spontaneously. Erythromycin administered at high dose (12 $\mathrm{mg} / \mathrm{kg} / \mathrm{hr}$ ) produces a different effect on gastric motility. ${ }^{31} \mathrm{It}$ does not induce antral phase III activity after infusion but induces high amplitude antral pressure wave during the first hour. ${ }^{31}$ In contrast, octreotide initiates small intestinal phase III activity but suppresses antral phase III activity during fasting and post-prandial period in healthy subjects within 30 minutes after injection. $^{32,34,35}$ These increased intestinal phase III activities have longer duration and greater propagation velocity than spontaneous migratory complexes and are associated with decreased phase II duration. ${ }^{34,35}$ It has been reported that octreotide can restore stomach and small intestinal motility in scleroderma patients with intestinal pseudo-obstruction to the contraction profiles which are similar to those of healthy controls. ${ }^{34}$ The provocative tests may provide benefit for evaluation of therapeutic response of 
these agents which may be associated with long-term positive effect (Fig. 1 and 2). ${ }^{32,34,36}$

During the study, simultaneous recording of GI symptoms such as nausea, vomiting, abdominal pain and the patient activities during position change and sleep are useful in correlating abnormal manometric findings to the symptoms, excluding artifact

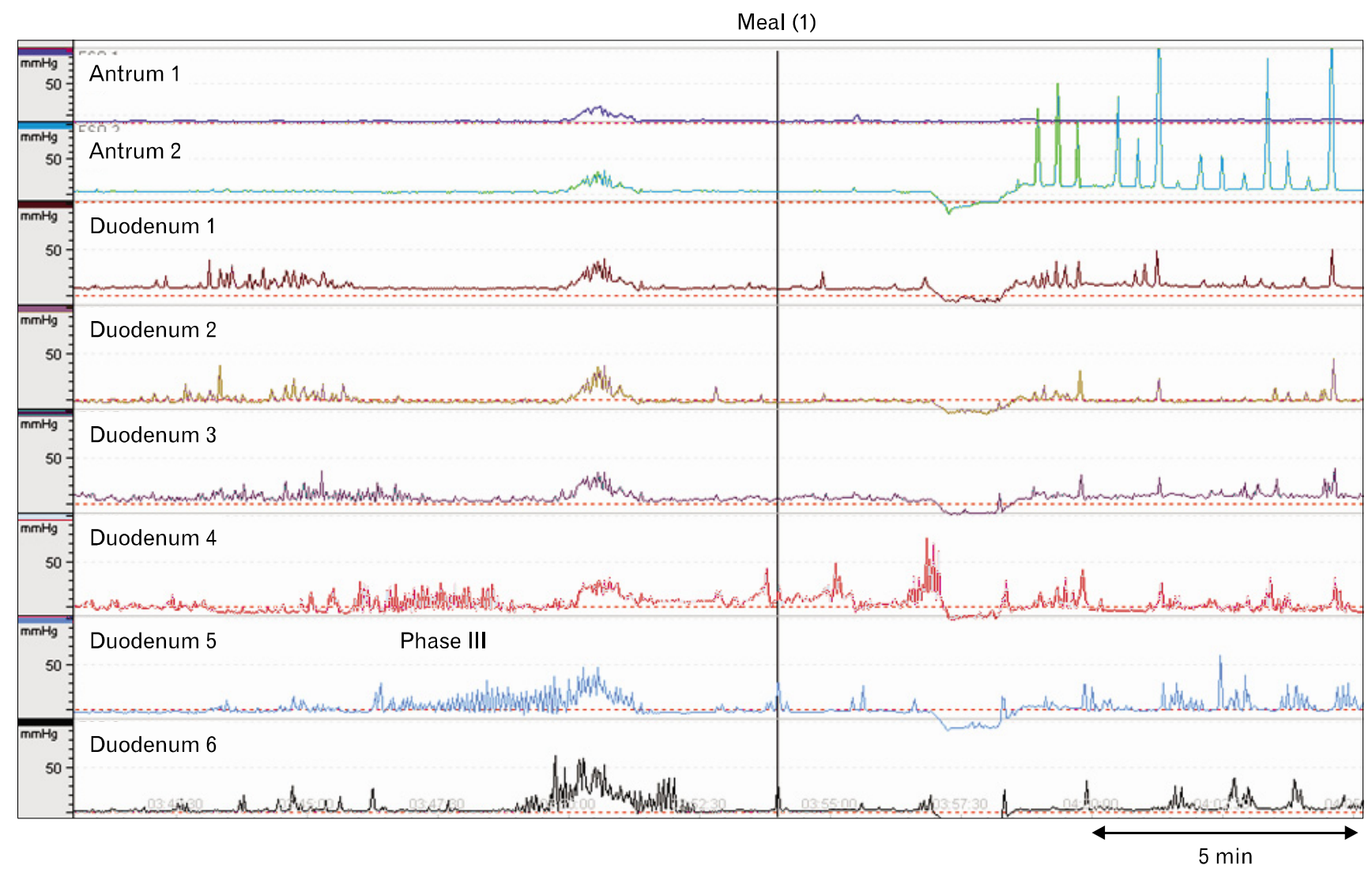

Figure 1. "Fed-response" - a termination of migratory motor complex then irregular and frequent contractions occurred immediately after meal ingestion.

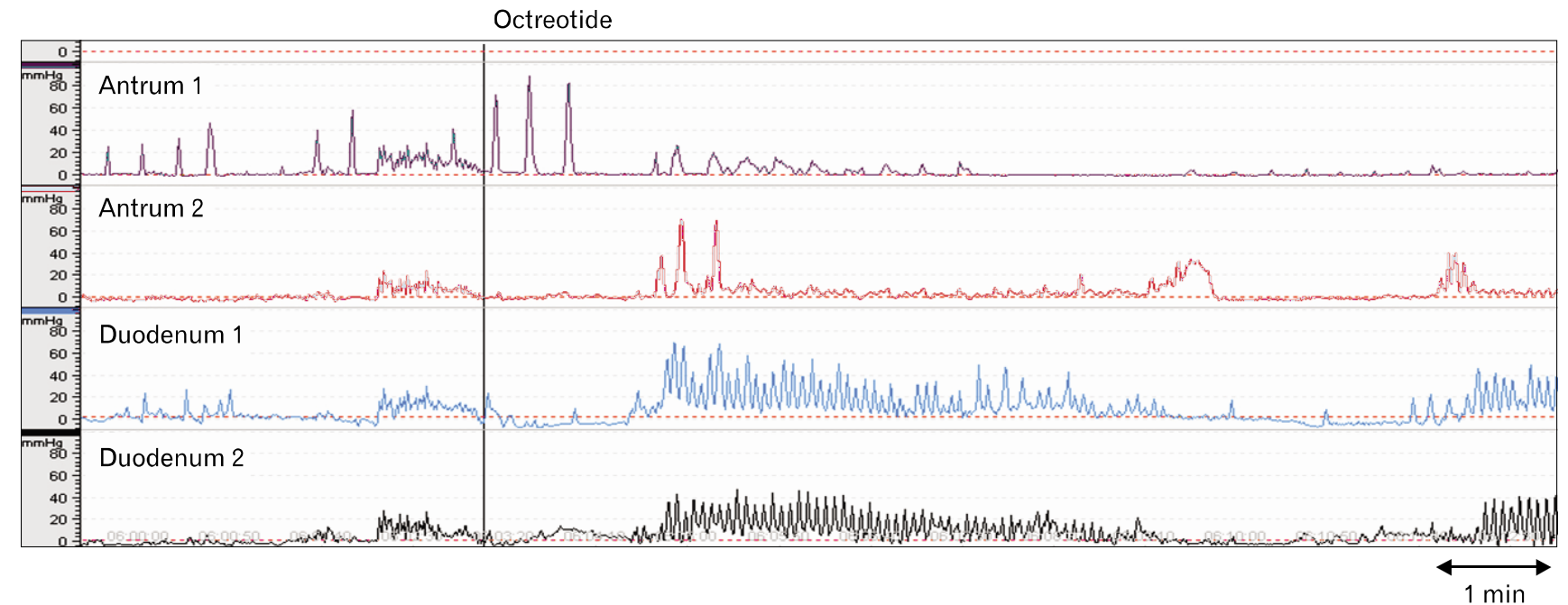

Figure 2. After octreotide injection, phase III antral contractions (at most upper channel) were inhibited but duodenal contractions (lower channels) were stimulated (phase III MMC like activity with rapid propagation). 
from analysis and determining the normal physiologic changes during waking vs. sleeping periods. In diabetes patients, plasma glucose should be periodically monitored and recorded. It has been reported that in healthy subjects hyperglycemia (plasma glucose $>15 \mathrm{mmol} / \mathrm{L}$ ) inhibits antral motility and increases duodenal MMC cycle frequency which have resulted from a significantly shorter duration of phase II MMC. ${ }^{37}$ Stressors also have been demonstrated to affect intestinal motility. While acute psychological stress suppresses duodenal and jejunal phase II MMC in healthy subjects ${ }^{38}$, vertigo and cold pain stimuli disrupt antral fed response with appearance of phase III MMC during post-prandial period. ${ }^{39}$

\section{Interpretation}

\section{Normal Antroduodenal Manometry Findings}

First, the overall nature of contractile activity recorded should be displayed and specific areas of interest can be viewed selectively. The highest amplitude and contraction frequency of each recording site should be noted to determine the location of recording site whether it is in antrum, pylorus or duodenum. The highest contraction frequency can be used as the marker for sensor location (3 cycle/min for the stomach and 11-12 cycle/min for the duodenum). Movement artifacts which were identified as simultaneous pressure changes at all channels should be eliminated from analysis. Only a pressure fluctuation more than $10 \mathrm{mmHg}$ is designated as a contraction. ${ }^{22,40}$

During fasting period, the presence of 3 distinct phases of $\mathrm{MMC}$ is analyzed as their presence, propagation and duration. The most characteristic of these contraction patterns which easily recognized is the phase III contraction. In this phase of the $\mathrm{MMC}$, antral contractions are regular and strong at slow wave frequency at 3 (2-4) cycles per minute (cpm) and amplitude of more than $40 \mathrm{mmHg}{ }^{28,41}$ The contraction frequency of duodenum is between 11-12 cpm with amplitude of more than 20 $\mathrm{mmHg}$ during the phase III MMC. ${ }^{28,41}$ Most of the phase III contractions begin in duodenum but it can originate in the antrum and then migrate into small intestine. ${ }^{41}$ This phase lasts about 3-4 minutes. ${ }^{30}$ After phase III contractions terminate, phase I contractions, which are quiescent phase contractions, always occur and last for 40-50 minutes, followed by phase II contraction which is irregular, more frequent with maximum rate less than the slow wave frequency $(3 \mathrm{cpm}$ at antrum and $11 \mathrm{cpm}$ at duodenum). ${ }^{30}$ An absence of MMC during 24-hour period is considered abnormal. ${ }^{30,40}$ Prolonged ambulatory antroduodenal manometry in healthy volunteers showed that the contraction pattern during sleeping is different from waking. ${ }^{40,42} \mathrm{MMC}$ duration during sleeping is shorter with mean duration of 80 minutes compare to 100 minutes during waking. Phase III contractions significantly occurred more frequently (5 MMC/24 hr vs. 2 $\mathrm{MMC} / 24 \mathrm{hr}$ ) together with shorter duration of phase II and lower phase II activity than waking period. No cluster contraction was observed in sleeping period. In both sleeping and waking periods, most of the MMCs originated from duodenum and the propagation velocity was reported to be similar. Moreover, sleeping significantly reduces the fed pattern duration with no difference in the onset of fed pattern after meal ingestion. ${ }^{40,42}$ Therefore, during the antroduodenal manometry study, the sleeping and waking periods should be recorded in a patient diary.

The MMC at fasting period is terminated immediately after meal ingestion and converted to the post-prandial contraction pattern or fed-response. The fed period ends when the phase III MMC returns and usually lasts at least 2 hours after meal ingestion. ${ }^{40}$ During the postprandial phase, the high amplitude and irregular contractions are seen in gastric antrum which represent the mixing and grinding of solid food, whereas the lower amplitude and irregular contractions are seen in duodenum as long as there are nutrients in the lumen. The duration of this phase is dependent on food calories and consistency. A study using solid meal demonstrated that $300 \mathrm{kcal}$ diet induced more prolonged fed response duration than $150 \mathrm{kcal}$ diet (mean duration $359 \mathrm{mi}-$ nutes vs. 177 minutes, respectively), whereas $600 \mathrm{kcal}$ diet failed to prolong the fed pattern duration than $300 \mathrm{kcal}$ diet. The amplitude of contractions was not significantly affected by the amount of meal calories. ${ }^{43,44}$ The other studies comparing different calories and diet composition in liquid solution demonstrated that fed pattern duration was significantly prolonged with $300 \mathrm{kcal}$ liquid diet than water and $600 \mathrm{kcal}$ meals induced higher fed pattern duration than $300 \mathrm{kcal}$. However, different composition including fat and glucose with the same calories amount, had similar effect on post-prandial contraction duration, frequency and amplitude. ${ }^{45,46}$ Therefore, the diet of higher calories or a solid meal induces more prolonged post-prandial motor activity than the lower calories diet or a liquid meal and at least $220 \mathrm{kcal}$ of solid meal has been demonstrated to induce the fed pattern. ${ }^{43}$ Post-prandial motor activity was similar between day time and night time. ${ }^{43}$ In our center, we use a caloric liquid meal (Ensure ${ }^{\circledR}$ $250 \mathrm{~mL}, 250 \mathrm{kcal}$ ) as a standard meal to study a fed response during antroduodenal manometry. The amount of ingested meal 
should be recorded.

\section{Clinical Utility}

Several patterns of abnormal antroduodenal contractions have been described and these findings can provide information on symptom pathophysiology, change the diagnosis and have impact on the patient management.

\section{Myopathic Pattern}

The migratory motor complex cycle is controlled mainly by myenteric plexus in the gut wall. In patients with visceral myopathy, the MMC is often preserved but very low amplitude contractions $\left(<20 \mathrm{mmHg}\right.$ ) are usually found. ${ }^{47}$ The stomach contractions can be preserved during early stage. This myopathic pattern can be found in patients with systemic sclerosis, ${ }^{48}$ amyloidosis, ${ }^{49}$ muscular dystrophy ${ }^{50}$ and familial visceral myopathy. ${ }^{50,51}$ However, in late stage of severe visceral myopathy patients, the normal MMC pattern may be absent or cannot be identified due to very low amplitude of contractions.

\section{Neuropathic Pattern}

In the intrinsic (enteric) neuropathic process, normal amplitude contractions are preserved but the un-coordinated or disorganized configuration or propagation of MMC or phase III MMC is demonstrated (Fig. 3). ${ }^{47}$ In contrast, in the extrinsic (autonomic) neuropathy, an impaired fed response and postprandial antral hypomotility are observed. ${ }^{47}$

Several neuropathic patterns have been reported to be associated with intestinal pseudo-obstruction. ${ }^{1}$ These include bursts of non-propagated phasic pressure activity (duration $>2 \mathrm{mi}$ nutes, amplitude $>20 \mathrm{mmHg}$, frequency $>10$ waves/minute) during fasting period and/or fed state, sustained incoordinated fasting pressure activity (duration $>30$ minutes) and inability of an ingested meal to convert fasting into fed pattern.

Among type 1 diabetes and long-standing type 2 diabetes, most of the GI motility abnormalities are consistent with autonomic neuropathy. Infrequent antral component of MMC and infrequent antral contraction during post-prandial period with normal amplitude or antral hypomotility have been reported. ${ }^{52,53}$

Since the phase III MMC is essential for clearing the indigestible materials from the stomach downward through the

Phase II

Phase II

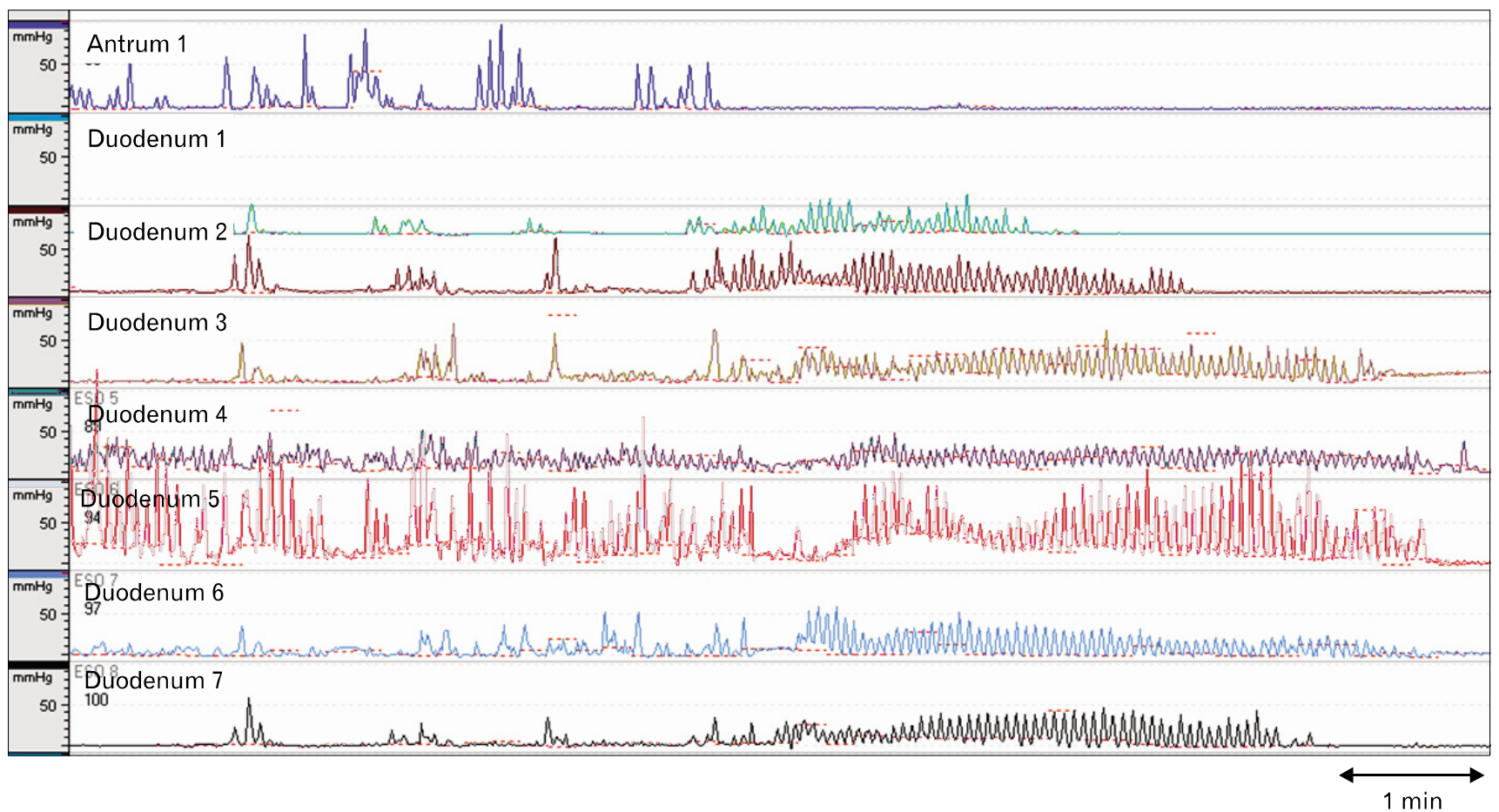

Figure 3. A case of intestinal pseudo-obstruction - burst of phase II contractions and disorganized phase III migratory motor complex (both antegrade and retrograde phase III MMC) were demonstrated. 
small intestine and colon, a decreased occurrence or absence of phase III MMC has been found to be associated with the presence of gastric bezoars and small intestinal bacterial overgrowth. ${ }^{54}$

\section{Mechanical Obstruction}

Differentiation of small intestinal pseudo-obstruction and mechanical obstruction is crucial. In some patients, clinical evaluation and investigation including radiology are unable to make definite diagnosis. The manometric features of mechanical obstruction have been described including non-propagated and prolonged contraction (8 seconds), non-propagated cluster contraction or bursts of rhythmic phasic activity that last more than 30 minutes and mix of these patterns with positive predictive value of $82 \%, 57 \%$ and $56 \%$; respectively. ${ }^{5}$

\section{Vomiting Versus Rumination Pattern}

Among patients with unexplained vomiting, antroduodenal manometry is able to identify the underlying mechanism of the vomiting symptoms. High amplitude ( $>30 \mathrm{mmHg}$ ), retrograde peristaltic contractions of small intestine from distal to proximal part preceded a vomiting episode, then was followed by phase III contractions, which is the characteristic of spontaneous vomiting process caused by intestinal contractions. ${ }^{55}$ The other mechanism is retching, in which simultaneous contractions at all sensors are observed during vomiting. These contractions represent abdominal wall contractions but not intestinal contractions and can be found in rumination syndrome (Fig. 4).

\section{Functional Gastrointestinal Disorders}

The role of disturbance in gut motor activities on pathogenesis of functional GI disorders and symptoms has not been clearly understood. ${ }^{56}$ Several stomach and intestinal motor abnormalities have been reported in patients with unexplained upper GI symptoms and irritable bowel syndrome. ${ }^{7,10,22,57,58}$ A decreased antral phasic pressure activity after a solid meal and unpropagated bursts of phasic and tonic contractile activity were a rela-

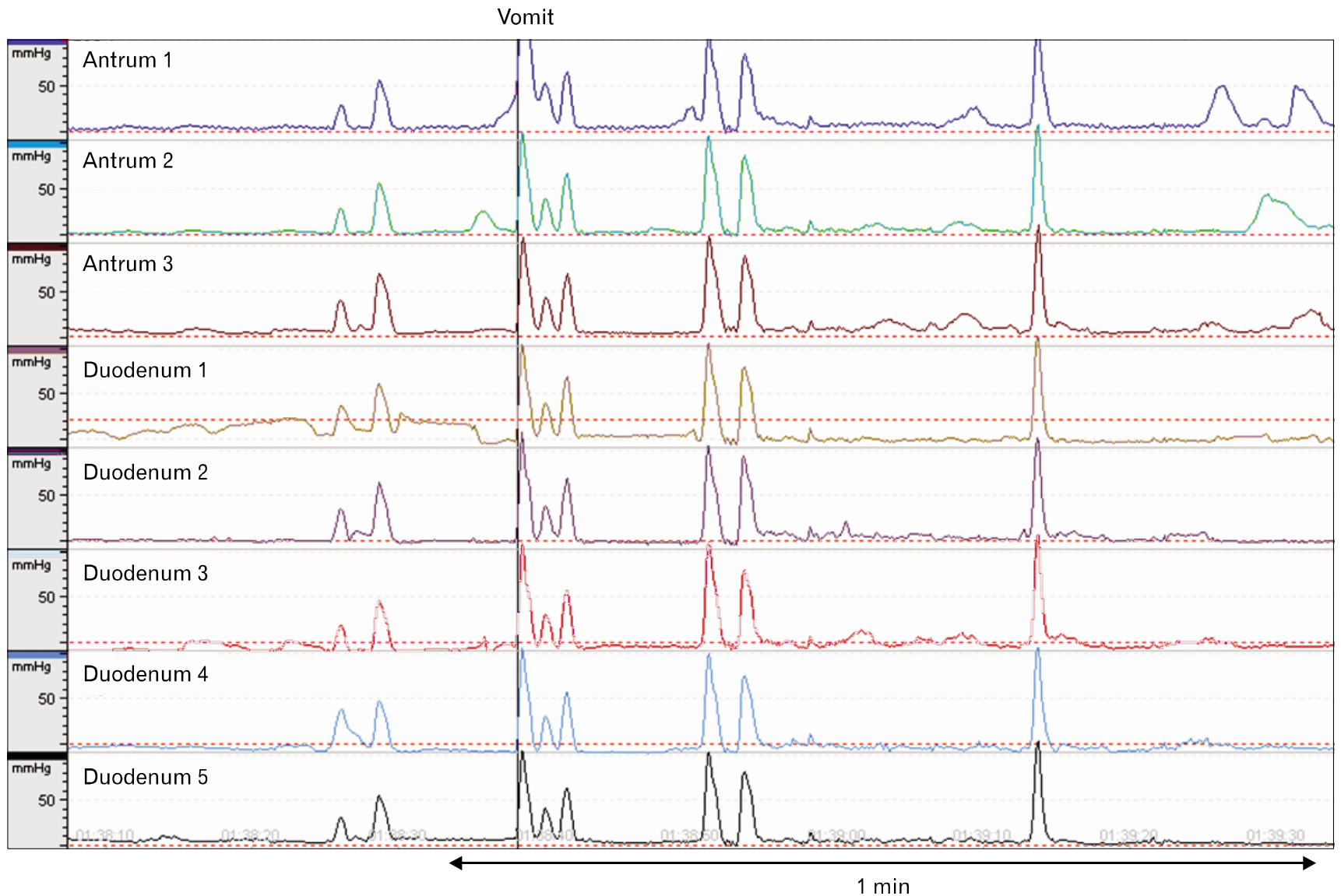

Figure 4. A case of chronic vomiting - simultaneous contractions at all sensors which represent abdominal wall contractions were demonstrated of all vomiting events. Rumination syndrome was a final diagnosis in this patient. 


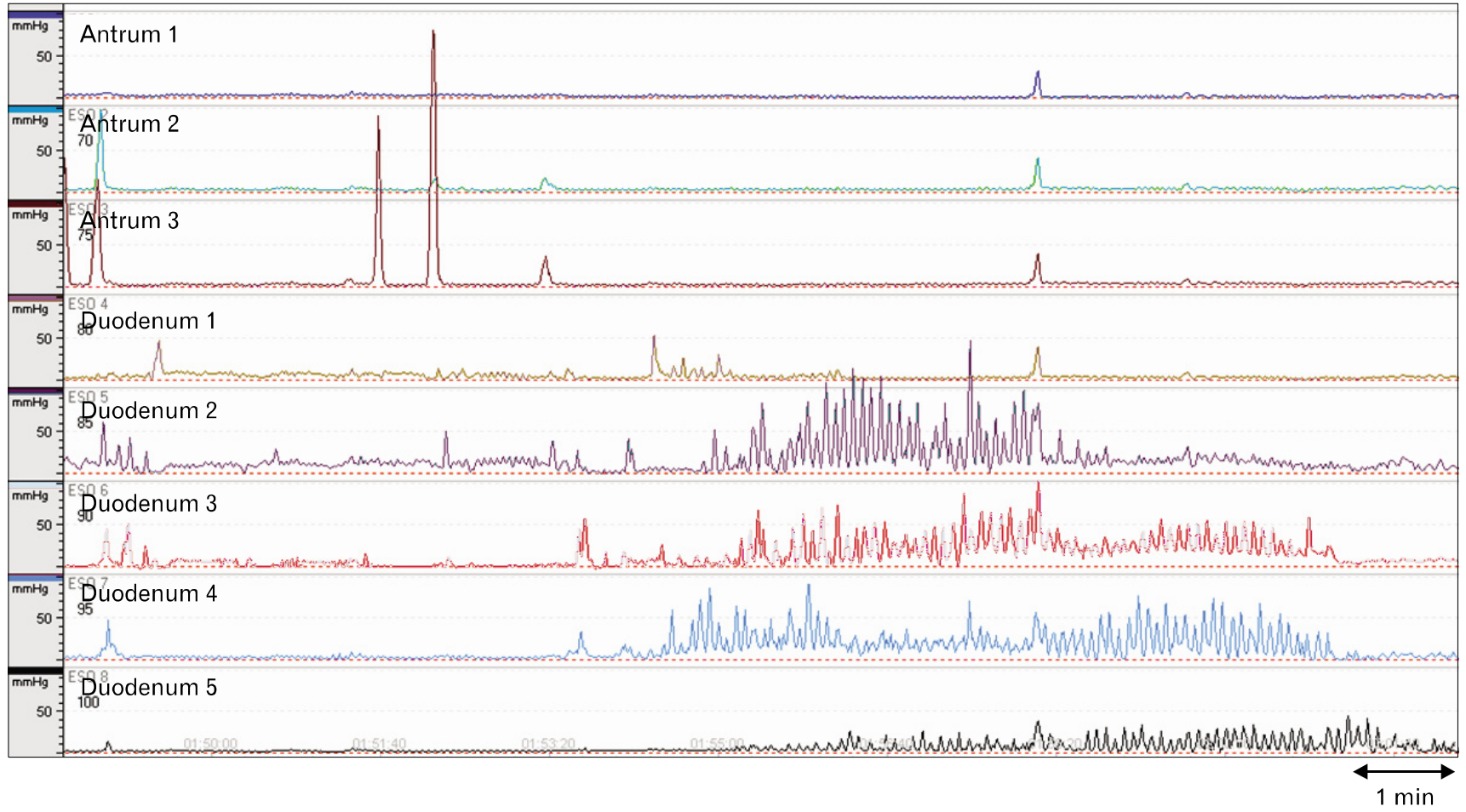

Figure 5. A case of severe abdominal pain - retrograde phase III of the fasting migrating motor complex was demonstrated.

tively frequent abnormalities among patients with nausea, vomiting, upper abdominal pain or functional dyspepsia than control subjects. ${ }^{7}$ During prolonged fasting, an absence of phase III MMC, unpropagated bursts of phasic and tonic activity of phase II contractions, and retrograde contractions were also reported (Fig. 5) ${ }^{58}$ Cluster contractions, defined as a burst of uninterrupted rhythmic phasic pressure waves at the usual phasic frequency for that site, last longer than 30 seconds and are separated by a period of quiescence of at least 30 seconds at jejunum. Ileal propulsive waves have been found more commonly in irritable bowel syndrome patients than controls. ${ }^{59}$

\section{Conclusions}

Antroduodenal manometry is a valuable diagnostic tool for several GI motility disorders and the results which based on the disease pathophysiology may be useful for physician to manage directly. The use of new technique or HRM system may be more simple to perform and interpret. However, more case-controlled studies are needed and the relevance of the motor abnormalities to symptom induction has to be proved.

\section{References}

1. Verhagen MA, Samsom M, Jebbink RJ, Smout AJ. Clinical relevance of antroduodenal manometry. Eur J Gastroenterol Hepatol 1999;11:523-528.

2. Ghoshal UC, Paliwal M, Das K, Yachha SK, Sachdeva S, Misra A. Antroduodenal manometry: experience from a tertiary care center. Indian J Gastroenterol 2008;27:53-57.

3. Stanghellini V, Cogliandro R, Cogliandro L, et al. Clinical use of manometry for the diagnosis of intestinal motor abnormalities. Dig Liver Dis 2000;32:532-541.

4. Stanghellini V, Camilleri M, Malagelada JR. Chronic idiopathic intestinal pseudo-obstruction: clinical and intestinal manometric findings. Gut 1987;28:5-12.

5. Frank JW, Sarr MG, Camilleri M. Use of gastroduodenal manometry to differentiate mechanical and functional intestinal obstruction: an analysis of clinical outcome. Am J Gastroenterol 1994; 89:339-344.

6. Cucchiara S, Borrelli O, Salvia G, et al. A normal gastrointestinal motility excludes chronic intestinal pseudoobstruction in children. Dig Dis Sci 2000;45:258-264.

7. Malagelada JR, Stanghellini V. Manometric evaluation of functional upper gut symptoms. Gastroenterology 1985;88(5 Pt 1):1223-1231.

8. Glia A, Lindberg G. Antroduodenal manometry findings in patients with slow-transit constipation. Scand J Gastroenterol 1998;33:55-62.

9. Glia A, Akerlund JE, Lindberg G. Outcome of colectomy for 
slow-transit constipation in relation to presence of small-bowel dysmotility. Dis Colon Rectum 2004;47:96-102.

10. Quigley EM, Donovan JP, Lane MJ, Gallagher TF. Antroduodenal manometry. Usefulness and limitations as an outpatient study. Dig Dis Sci 1992;37:20-28.

11. Heddle R, Dent J, Toouli J, Read NW. Topography and measurement of pyloric pressure waves and tone in humans. Am J Physiol 1988;255(4 Pt 1):G490-G497.

12. Desipio J, Friedenberg FK, Korimilli A, Richter JE, Parkman HP, Fisher RS. High-resolution solid-state manometry of the antropyloroduodenal region. Neurogastroenterol Motil 2007;19:188-195.

13. Andrews JM, O'donovan DG, Hebbard GS, Malbert CH, Doran SM, Dent J. Human duodenal phase III migrating motor complex activity is predominantly antegrade, as revealed by high-resolution manometry and colour pressure plots. Neurogastroenterol Motil 2002;14:331-338.

14. Mearin F, Camilleri M, Malagelada JR. Pyloric dysfunction in diabetics with recurrent nausea and vomiting. Gastroenterology 1986; 90:1919-1925.

15. Miller LS, Szych GA, Kantor SB, et al. Treatment of idiopathic gastroparesis with injection of botulinum toxin into the pyloric sphincter muscle. Am J Gastroenterol 2002;97:1653-1660.

16. Arts J, Holvoet L, Caenepeel P, et al. Clinical trial: a randomized-controlled crossover study of intrapyloric injection of botulinum toxin in gastroparesis. Aliment Pharmacol Ther 2007;26:1251-1258.

17. Arts J, van Gool S, Caenepeel P, Verbeke K, Janssens J, Tack J. Influence of intrapyloric botulinum toxin injection on gastric emptying and meal-related symptoms in gastroparesis patients. Aliment Pharmacol Ther 2006;24:661-667.

18. Friedenberg FK, Palit A, Parkman HP, Hanlon A, Nelson DB. Botulinum toxin A for the treatment of delayed gastric emptying. Am J Gastroenterol 2008;103:416-423.

19. Treacy PJ, Jamieson GG, Dent J. The effect of duodenal distension upon antro-pyloric motility and liquid gastric emptying in pigs. Aust N Z J Surg 1996;66:37-40.

20. Edelbroek M, Horowitz M, Dent J, et al. Effects of duodenal distention on fasting and postprandial antropyloroduodenal motility in humans. Gastroenterology 1994; 106:583-592.

21. Castedal M, Björnsson E, Abrahamsson H. Effects of midazolam on small bowel motility in humans. Aliment Pharmacol Ther 2000;14: 571-577.

22. Byrne KG, Quigley EM. Antroduodenal manometry: an evaluation of an emerging methodology. Dig Dis 1997;15(suppl 1):53-63.

23. Penning C, Gielkens HA, Hemelaar M, Lamers CB, Masclee AA. Reproducibility of antroduodenal motility during prolonged ambulatory recording. Neurogastroenterol Motil 2001;13:133-141.

24. Wilson P, Perdikis G, Hinder RA, Redmond EJ, Anselmino M, Quigley EM. Prolonged ambulatory antroduodenal manometry in humans. Am J Gastroenterol 1994;89:1489-1495.

25. Quigley EM. Intestinal manometry in man: a historical and clinical perspective. Dig Dis 1994;12:199-209.

26. Jebbink RJ, vanBerge-Henegouwen GP, Akkermans LM, Smout AJ. Antroduodenal manometry: 24-hour ambulatory monitoring versus short-term stationary manometry in patients with functional dyspepsia. Eur J Gastroenterol Hepatol 1995;7:109-116.

27. Soffer EE, Thongsawat S. Small bowel manometry: short or long re- cording sessions? Dig Dis Sci 1997;42:873-877.

28. Thumshirn M, Bruninga $K$, Camilleri M. Simplifying the evaluation of postprandial antral motor function in patients with suspected gastroparesis. Am J Gastroenterol 1997;92:1496-1500.

29. Camilleri M. Jejunal manometry in distal subacute mechanical obstruction: significance of prolonged simultaneous contractions. Gut 1989;30:468-475.

30. Holland R, Gallagher MD, Quigley EM. An evaluation of an ambulatory manometry system in assessment of antroduodenal motor activity. Dig Dis Sci 1996;41:1531-1537.

31. Bjornsson ES, Abrahamsson H. Comparison between physiologic and erythromycin-induced interdigestive motility. Scand J Gastroenterol 1995;30:139-145.

32. Chen JD, Lin ZY, Edmunds MC 3rd, McCallum RW. Effects of octreotide and erythromycin on gastric myoelectrical and motor activities in patients with gastroparesis. Dig Dis Sci 1998;43:80-89.

33. Di Lorenzo C, Lucanto C, Flores AF, Idries S, Hyman PE. Effect of sequential erythromycin and octreotide on antroduodenal manometry. J Pediatr Gastroenterol Nutr 1999;29:293-296.

34. Owyang C. Octreotide in gastrointestinal motility disorders. Gut 1994;35(suppl):S11-S14.

35. Haruma K, Wiste JA, Camilleri M. Effect of octreotide on gastrointestinal pressure profiles in health and in functional and organic gastrointestinal disorders. Gut 1994;35:1064-1069.

36. Verne GN, Eaker EY, Hardy E, Sninsky CA. Effect of octreotide and erythromycin on idiopathic and scleroderma-associated intestinal pseudoobstruction. Dig Dis Sci 1995;40:1892-1901.

37. Gielkens HA, Verkijk M, Frölich M, Lamers CB, Masclee AA. Is the effect of acute hyperglycaemia on interdigestive antroduodenal motility and small-bowel transit mediated by insulin? Eur J Clin Invest 1997;27:703-710.

38. Kellow JE, Langeluddecke PM, Eckersley GM, Jones MP, Tennant CC. Effects of acute psychologic stress on small-intestinal motility in health and the irritable bowel syndrome. Scand J Gastroenterol 1992;27:53-58.

39. Stanghellini V, Malagelada JR, Zinsmeister AR, Go VL, Kao PC. Stress-induced gastroduodenal motor disturbances in humans: possible humoral mechanisms. Gastroenterology 1983;85:83-91.

40. Bortolotti M, Annese V, Coccia G. Twenty-four hour ambulatory antroduodenal manometry in normal subjects (co-operative study). Neurogastroenterol Motil 2000;12:231-238.

41. Kellow JE, Borody TJ, Phillips SF, Tucker RL, Haddad AC. Human interdigestive motility: variations in patterns from esophagus to colon. Gastroenterology 1986;91:386-395.

42. Kumar D, Soffer EE, Wingate DL, Britto J, Das-Gupta A, Mridha K. Modulation of the duration of human postprandial motor activity by sleep. Am J Physiol 1989;256(5 Pt 1):G851-G855.

43. Schönfeld J, Evans DF, Wingate DL. Daytime and night time motor activity of the small bowel after solid meals of different caloric value in humans. Gut 1997;40:614-618.

44. Schönfeld J, Evans DF, Goebell H, Wingate DL. Comparison of the small bowel motor response to solid and liquid meals in man. Digestion 1997;58:402-406.

45. Schönfeld V. Small bowel motor activity in response to physiological meals of different chemical composition in man. Z Gastroenterol 2006;44:231-234. 
46. von Schönfeld J, Evans DF, Renzing K, Castillo FD, Wingate DL. Human small bowel motor activity in response to liquid meals of different caloric value and different chemical composition. Dig Dis Sci 1998;43:265-269.

47. Bharucha AE, Camilleri M, Low PA, Zinsmeister AR. Autonomic dysfunction in gastrointestinal motility disorders. Gut 1993;34:397401.

48. Sjölund K, Bartosik I, Lindberg G, Scheja A, Wildt M, Akesson A. Small intestinal manometry in patients with systemic sclerosis. Eur J Gastroenterol Hepatol 2005;17:1205-1212.

49. Tada S, Iida M, Yao T, Kitamoto T, Yao T, Fujishima M. Intestinal pseudo-obstruction in patients with amyloidosis: clinicopathologic differences between chemical types of amyloid protein. Gut 1993;34: 1412-1417.

50. Husebye E. The patterns of small bowel motility: physiology and implications in organic disease and functional disorders. Neurogastroenterol Motil 1999;11:141-161.

51. Chokhavatia S, Anuras S. Neuromuscular disease of the gastrointestinal tract. Am J Med Sci 1991;301:201-214.

52. Samsom M, Jebbink RJ, Akkermans LM, Berge-Henegouwen GP, Smout AJ. Abnormalities of antroduodenal motility in type I diabetes. Diabetes Care 1996;19:21-27.
53. Camilleri M, Malagelada JR. Abnormal intestinal motility in diabetics with the gastroparesis syndrome. Eur J Clin Invest 1984;14: 420-427.

54. Pimentel M, Soffer EE, Chow EJ, Kong Y, Lin HC. Lower frequency of MMC is found in IBS subjects with abnormal lactulose breath test, suggesting bacterial overgrowth. Dig Dis Sci 2002;47: 2639-2643.

55. Thompson DG, Malagelada JR. Vomiting and the small intestine. Dig Dis Sci 1982;27:1121-1125.

56. Camilleri M, McKinzie S, Busciglio I, et al. Prospective study of motor, sensory, psychologic, and autonomic functions in patients with irritable bowel syndrome. Clin Gastroenterol Hepatol 2008;6:772781.

57. Sha W, Pasricha PJ, Chen JD. Correlations among electrogastrogram, gastric dysmotility, and duodenal dysmotility in patients with functional dyspepsia. J Clin Gastroenterol 2009;43:716-722.

58. Björnsson ES, Abrahamsson H. Contractile patterns in patients with severe chronic dyspepsia. Am J Gastroenterol 1999;94:54-64.

59. Kellow JE, Phillips SF. Altered small bowel motility in irritable bowel syndrome is correlated with symptoms. Gastroenterology 1987;92: 1885-1893. 